\title{
Support Vector Machine Cost Estimation Model for Road Projects
}

\author{
Nabil Ibrahim El-Sawalhi \\ Faculty of Engineering, Islamic University, Gaza 00972, Palestine
}

\begin{abstract}
A cost estimate is one of the most important steps in road project management. There are ranges of factors that mostly affect the final project cost. Many approaches were used to estimate project cost, which took into consideration probable project performance and risks. The aim is to improve the ability of construction managers to predict a parametric cost estimate for road projects using SVM (support vector machine). The work is based on collecting historical road executed cases. The 12 factors were identified to be the most important factors affecting the cost-estimating model. A total of 70 case studies from historical data were divided randomly into three sets: training set includes 60 cases, cross validation set includes three cases and testing set includes seven cases. The built model was successfully able to predict project cost to the AP (accuracy performance) of $95 \%$.
\end{abstract}

Key words: Road projects, parametric cost estimation, support vector machine, cross validation.

\section{Introduction}

The construction industry is one of the major industries significantly contributing in the growth of socio-economic development. Construction projects in the Gaza Strip suffer from many problems and complex issues in performance, such as cost, time and safety. Achieving project completion on time and within budget at specified quality standards is a major criterion of project success. The aim of this research is to identify and evaluate the most important parameters affecting the cost of the road projects in the Gaza Strip and to predict the parametric cost estimate of road projects using SVM (support vector machines).

\section{Early Cost Estimating}

Construction estimate is one of the most crucial functions in project management. Cost estimating needs to be done in different methods at different stages of a project. At the early stage where the project budget is to be decided, detailed information is not available and parametric cost estimating techniques are

Corresponding author: Nabil Ibrahim El-Sawalhi, associate professor, research fields: project management, decision making, risk analysis and quality management. E-mail: nsawalhi@iugaza.edu.ps. most applicable.

At all estimating levels, the difficulties involved often result in many mistakes and errors in judgment. However, preliminary (parametric) estimating exhibits the lowest accuracy level due to the lack of project information and the high level of uncertainty at this early stage of a project [1]. A project cost is affected by numerous factors [2].

Road project will refer to the development or improvement of land transport systems, public buildings, energy networks, and water supply and treatment works. The basic aim of a road project is to implement an economically beneficial improvement whose objectives are determined in terms of technical performance, budget and timescale. The development of road projects is a complex and resource-intensive process.

No two road projects will cost the same amount of money no matter how similar they are. Apart from basic technical factors, the wide range of economic and institutional conditions in different member states will itself always lead to variations. Nevertheless, the fundamental project costs are based on the actual cost of the land, materials, equipment and labor in the 
region where the project is being procured [3].

Money is always of special importance to those involved in the construction project. Cost is among the major considerations throughout the project management life cycle, can be regarded as one of the most important parameters of a project and the driving force of project success, and is of high concern for those who are involved in the construction industry. The success of any project highly depends on adequate availability and efficient management of various resources [4]. Despite its proven importance, it is common to see a construction project failing to achieve its objectives within the specified cost. However, studies show that projects are rarely complete within stipulated budget [5].

A cost overrun is a very frequent phenomenon and is almost associated with nearly all projects in the construction industry [5]. Cost overrun of road projects has become a common problem for transportation. Mahamid and Bruland [6] investigated the statistical relationship between actual and estimated cost of road construction projects using data from road construction projects implemented in the west bank in Palestine over the years 2004-2008. The study was based on a sample of 169 road construction projects. They found that $100 \%$ of projects are suffering from cost diverge. It is found that $76.33 \%$ of the projects have cost over estimation while $23.67 \%$ have cost underestimation. They also concluded that the discrepancy between estimated and actual cost has an average of $14.56 \%$, ranging from $39.27 \%$ to $98.04 \%$.

A key factor for a successful project is the preparation of an accurate estimate, which can influence factors ranging from project feasibility to profitability. Accurate estimation of the construction cost of a project is extremely important. One of the most unpleasant bits of news you may ever have to deliver to a client is that the cost of a project will be more than you had estimated. Construction estimate is the cost of physically constructing the project in the time required based on current costs for labor, materials, equipment, mobilization, bonds and profit [7].

Construction cost estimating usually proceeds in one of two ways, either the client provides the designer with a maximum budget figure, the limit for construction costs, or there is a preliminary period of study (under the schematic design phase) in which possible schemes are developed and their respective costs estimated. The preparation of a cost estimate of the project is one of the most difficult tasks in project management because it must be done before the work is accomplished [8]. Estimates should be developed using the best information available. When preparing any estimate, engineering judgment must be applied. The estimating team should be composed of experienced personnel, with the requisite technical, managerial, leadership and communication cost estimating skills. The team should also have a thorough understanding of the project's scope, including the ability to determine and evaluate critical issues and risks [9].

Pheng and Chuan [10] stated that there have been many past studies on project performance according to cost and time factors. Chan and Kumaraswamy [11] stated that a number of unexpected problems and changes from the original design arise during the construction phase, leading to problems in cost and time performance. Various studies have focused on identifying the factors that have some influence on the accuracy of estimating the costs of construction work. Based on previous studies, Gunner and Skitmore [12] identified 12 factors: building function, type of contract, conditions of contract, contract sum, price intensity, contract period, number of bidders, good/bad years, procurement basis, project sector (public, private or joint), number of priced items and number of drawings.

Mahamid [13] investigated the effect of projects' physical characteristics on cost deviation in road construction. The considered characteristics are: project size (i.e., small, medium and large), estimated cost, road length, road width, terrain conditions, soil and rock suitability, and soil and rock drill ability, 
method of construction, site constraints and location of the project. Ayed [1] shows parametric cost estimate is performed when detailed project information is lacking. The usable historical data at this level pertain to the characteristics of past projects (e.g., location, size and complexity), their construction environment (e.g., market, weather and year) in addition to the associated costs spent. The large number of these factors in addition to other external political, environmental and technological risks represents a complex problem in establishing accurate cost estimating models.

According to Major Project Program Cost Estimating Guidance [7], the following should be considered when preparing the construction cost estimate:

- Contracting method: innovative contracting techniques such as design-build, cost-plus-time bidding, lane rental, etc.;

- Surety issues: Obtaining bid and performance bonds for major projects are difficult, especially for smaller contractors. If bonding requirements are not reduced, then an increased amount for obtaining bonds should be included in the cost estimate;

- Bidding climate impact: Cost estimates have to consider the economic impact of the major project in the local geographical area. Cost estimates should take into account market conditions;

- Industry capacity: The number of potential qualified contractors may have a limiting effect of competition and would result in higher bids. If possible, rescheduling advertisement dates may be appropriate;

- Price adjustment (price indexing) contract provisions: the price volatility of construction materials and supplies such as asphalt, fuel, cement and steel can result in significant problems for contractors in preparing bids;

- Highly specialized designs and technology: Cost estimates should consider the impact of any requirement to use first-of-a-kind technology, new materials, or methods of construction;

- Construction time: The impacts of construction activities (e.g., sequencing, traffic control, haul routes, accessibility, geographic locations, roads damaged by construction equipment, and ponds that may be silted as part of construction) should be considered when developing cost estimates;

- Other factors: differing site conditions, contaminated soil, multi-agency involvement, context sensitive solutions and construction incentives.

El Asmar et al. [14] stated that there are many items affecting in making up the conceptual total project cost estimate, such as location of project, length, type of project, scope details, design parameters, site characteristics and broad design assumptions on which the estimate is based, earthwork, pavement, base and sub base, barrier wall, curb, gutter, traffic control, lighting, signing and marking, and electrical and mechanical requirements. The findings of Mahamid and Bruland [6] reveal that there are many factors affecting project cost estimate from consultants' point of view, which are materials price, experience in contracts, size of contract and incomplete drawings.

General forecasting techniques are quantitative approaches that have been used. They can be either deterministic or stochastic. Examples of deterministic methods are regression methods (linear regression and multiple regressions), econometric models moving average methods and exponential smoothing methods. Examples of stochastic methods are the maximum likelihood method, Box-Jankins models and probability weighted moment (L-moment). For instance, it may mean the determination of the life cycle cost of a system from a mathematical model containing a number of parameters and based on case histories of similar projects [1].

\section{Support Vector Machine}

SVMs (support vector machines) are used to predict the parametric cost estimation. An artificial intelligent technique is used to conduct the construction cost estimate. The theory of SVMs is a new statistical technique and has drawn much attention on this topic in 
recent years. This learning theory can be seen as an alternative training technique for polynomial, radial basis function and multi-layer percept classifiers [15].

The algorithms of SVMs solve a convex optimization problem in a relatively short time with a satisfying accurate solution. Applying SVMs, the conceptual construction cost estimate model is developed for owners and planners to predict the construction cost of a project [2]. SVMs are based on the idea of SRM (structural risk minimization) induction principle that aims at minimizing a bound on the generalization error, rather than minimizing the mean square error. In many applications, SVMs have been shown to provide higher performance than traditional learning machines and have been introduced as powerful tools for solving classification and regression problems. Cheng and $\mathrm{Wu}[2]$ stated that the equations of regression problems in SVMs are similar with the equations of classification problems except the target variables.

SVM is recognized as an attractive and promising tool to solve classification and regression related problems. Initial work on SVM as a classifier is focused on optical character recognition and object recognition tasks. SVM is one of the ML (machine learning) techniques derived from statistical learning theory by Gopalakrishnan and Kim [16]. It provides excellent generalization performance and sparse representation, making it more advantageous than other machine learning algorithms, such as NN (neural networks) [17]. Some of SVM applications in the civil engineering problems include conceptual cost estimates in construction projects, remote sensing image analysis, rainfall-runoff model and document classification for construction [16]. SVM has also provided excellent performances in regression and time-series prediction applications. Compared to regression approximation by conventional artificial NN, SVM has three distinct characteristics. SVM uses a set of linear functions defined in a high dimensional space. SVM carries out risk minimization using loss functions and it uses a risk function consisting of the empirical error and a regularization term which is derived from the SRM [16]. The points nearest to the separating hyperplane are called support vectors. They only determine the position of the hyperplane. All other points have no influence. Mathematically, the weighted sum of the support vectors is the normal vector of the hyperplane (Fig. 1).

SVM provides excellent generalization performance and sparse representation, making it more advantageous than other machine learning algorithms, such as NN. Generalization is the ability to capture unseen data attributes and sparse representation is the ability to deal with data that are sparse in input space provided a detailed description of the SVM algorithm. Essentially, the input space for a set of training samples is mapped into a higher dimensional feature space using either a linear or a nonlinear mapping function. Based on these mapping functions (kernel functions), SVM constructs an optimal separating hyperplane in the higher dimensional space that separates the classes with the least error and maximum margin. The margin represents the distance of the hyperplane to the neighboring data points of the different classes.

The larger the margin is, the lower is the generalization error of the SVM classifier. SVM has high dimensional input space, few irrelevant features

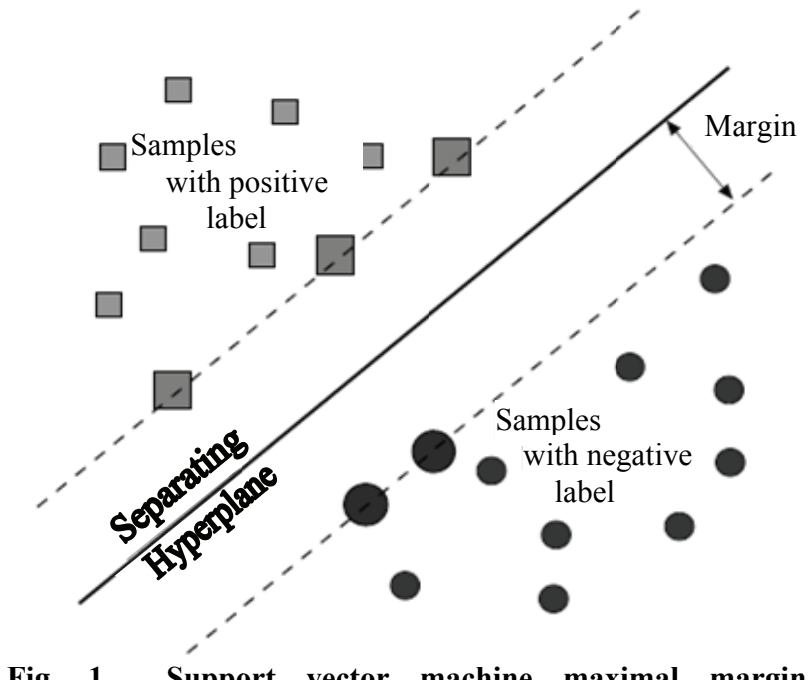

Fig. 1 Support vector machine maximal margin hyperplane in feature space. 
(dense concept), sparse document vectors (sparse instances), and text categorization problems are linearly separable [17].

\subsection{Properties of SVM}

The properties of SVM are as follows:

- flexibility in choosing a similarity function;

- sparseness of solution when dealing with large data sets. Only support vectors are used to specify the separating hyperplane;

- ability to handle large feature spaces. Complexity does not depend on the dimensionality of the feature space;

- over fitting which can be controlled by soft margin approach;

- nice math property: a simple convex optimization problem, which is guaranteed to converge to a single global solution;

- feature selection.

\subsection{SVM Applications}

SVM has been successfully used in many real-world problems: text (and hypertext) categorization, image classification, bioinformatics (protein classification, cancer classification) and hand-written character recognition.

\section{Research Methodology}

A questionnaire was used to collect opinions of experts in engineering project management about the most effective factors affecting cost estimation of road projects in Gaza Strip. The questionnaire consists of two major parts: first part is general information about the respondent; the other part of questionnaire contains 18 factors that affecting cost estimation in road projects collected from the literature review. A five-point scale was used to rate the agreement levels identified by the respondents from 1 (low effective) to 5 (high effective) factors. The questionnaire was distributed to 110 project managers in the Gaza Strip. Ninety-two correct questionnaires were received which represent $83.6 \%$ of the total targeted group.

The RII (relative importance index) was utilized in data analysis. This index was calculated by the equation:

$$
R I I=\left[\operatorname{Sum}\left(a_{i} \cdot x_{i}\right) / n\right] \times 100 \%
$$

where, $a_{i}$ is equal the weight of a response, $x_{i}$ is the frequency of the response, and $n$ is the number of weights. The sample mean was calculated by finding the average through adding all the numbers and dividing the sum by the amount of numbers that added. Three groups of experts were targeted: first is the owners, second is the consultants and the third is contractors who are working on road projects. The random selection among the three groups was done using non-replacement random selection.

\section{Results and Discussions}

The average percentage of the newly established companies (less than three years of experience) was $32 \%$ (29) among the three groups of construction professionals (contractors, consultants and owners) (Table 1).

The 32\% (29) contracting companies, 13\% (12) consulting offices and 55\% (51) owners firms participated in the questionnaire are shown in Fig. 2.

As demonstrated in Table 2, the majority of three groups executed more than five projects during the last five years. The high percentages $(48 \%$ who worked less than five projects) are attributed to two main reasons:

Table 1 Years of experience in the organization.

\begin{tabular}{llllc}
\hline Experience years of the organization & Contractor & Consultant & Owner & Average \\
\hline $1 \sim 3$ & 9 & 4 & 16 & $32 \%(29)$ \\
$4 \sim 6$ & 10 & 4 & 17 & $34 \%(31)$ \\
$7 \sim 10$ & 3 & 1 & 6 & $11 \%(10)$ \\
More than 10 & 7 & 3 & 12 & $24 \%(22)$ \\
\hline Total & $100 \%(29)$ & $100 \%(12)$ & $100 \%(51)$ & $100 \%(92)$ \\
\hline
\end{tabular}




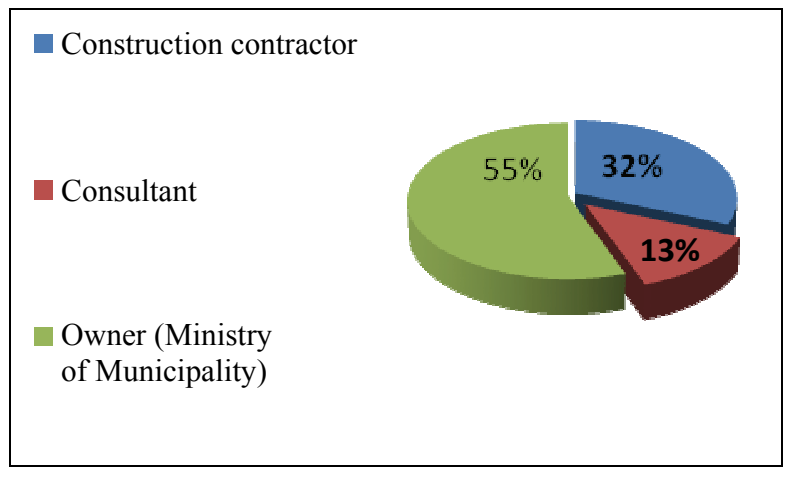

Fig. 2 Respondents' organizations.

the high numbers of the new established contracting companies. In addition to the current political situation, which contribute in reducing the numbers and the values of the construction projects? However, most of the participated companies have a good level of experience in the field of constructions.

The result in Table 3 depicts that the five most important factors positively affecting on pricing process in road projects in the Gaza Strip are: the ownership of the equipment, thickness of asphalt layer, the number of asphalt layers, area of the road and amount of cut and fill at the site with RII values of $0.835,0.830,0.810,0.790$ and 0.780 , respectively. On the other hand, results indicate the quality of base layer; thickness of "interlock" layer, indirect costs requested by the owner; standard size of asphalt mix (1/2" to $\left.3 / 4^{\prime \prime}\right)$; and specifications of curbstone were the lowest factors positively affecting on pricing process in roads projects in the Gaza Strip with RII values of 0.680, $0.660,0.653,0.650$ and 0.570 , respectively.

\section{Model Development}

SVM is an application/tool for providing models training and testing. NeuroSolution was used as a standalone environment for SVM development and implementation. Moreover, for verifying this work, a

Table 2 Numbers of executed projects.

\begin{tabular}{lllll}
\hline Number of executed projects & Contractor & Consultant & Owner & Average \\
\hline $1 \sim 5$ & 14 & 5 & 25 & $48 \%(44)$ \\
$6 \sim 10$ & 8 & 3 & 15 & $28 \%(26)$ \\
$11 \sim 15$ & 1 & 1 & 2 & $4 \%(4)$ \\
More than 15 & 6 & 3 & 9 & $20 \%(18)$ \\
\hline Total & $100 \%(29)$ & $100 \%(12)$ & $100 \%(51)$ & $100 \%(92)$ \\
\hline
\end{tabular}

Table 3 Factors affect pricing of roads construction projects.

\begin{tabular}{llll}
\hline An effective factor & Mean & RII & 16 \\
\hline Indirect costs requested by the owner & 3.3 & 0.653 & 9 \\
Contract type & 3.6 & 0.720 & 2 \\
Thickness of asphalt layer & 4.2 & 0.830 & 6 \\
Diameter of manholes & 3.7 & 0.74 & 7 \\
Depth of manholes & 3.6 & 0.570 & 18 \\
Curbstone type & 2.8 & 0.660 & 15 \\
Thickness of interlock & 3.3 & 0.725 & 11 \\
Existence of power network & 3.6 & 0.705 & 3 \\
Existence of infringements on the work site & 3.5 & 0.810 & 4 \\
The number of asphalt layers & 4.1 & 0.790 & 14 \\
Area of the road & 4.0 & 0.680 & 13 \\
Quality of the base layer & 3.4 & 0.690 & 12 \\
Thickness of the base layer & 3.5 & 0.700 & 17 \\
Quality of sub grade layer & 3.5 & 0.650 & 10 \\
Asphalt mix size (1/2" to 3/4") & 3.3 & 0.710 & 5 \\
Sewerage pipe diameters & 3.5 & 0.780 & 1 \\
Cut and fill at the site & 3.9 & 0.835 & \\
The ownership of the equipment & 4.2 & & \\
\hline
\end{tabular}


plentiful trial and error process was performed to obtain the best model architecture. To construct a model using support vector machine, the following steps were processed: model building, data collection and organization and model limitations, dividing the data to sets and building network and model training and testing.

\subsection{Model Building}

Many researchers have investigated different tools and applications used in construction management modeling. However, some few publications have studied the mechanism of support vector machine especially in road cost estimation compared with other widely used paradigm such as neural network model and traditional models.

Many software programs support the support vector machine models such as NeuroSolutions, LibSvm, SVM-Light, MATLAB and RapidMinor. NeuroSolution 5.07 for Excel program was used to develop the SVM model. NeuroSolution was selected for its ease of use, speed of training, flexibility of building and executing the SVM model. Finally, it has multiple criteria for training and testing.

\subsection{Data Collection and Organization}

Seventy road projects were collected from consultation offices, ministry of public works and other nongovernmental organizations. All collected projects are road related projects.

Data organizing is summarized through several steps as follows:

- save and sort the collected data in Excel sheet as columns (variables) and rows (projects);
- convert the encoded variables to coded variables;

- divide the columns into two groups: the first group is the input data, which consist of 12 most important factors identified from the field survey; the second group is the total cost of the project which is the desired output parameter.

\subsection{Model Limitations}

In this paper, most of road variables used in the Gaza Strip was included except those that have not enough frequency. After collecting and analyzing the data, some limitations were needed on input parameters to give the best output. Table 4 presents the variable range of input data in SVM model. These data were entered into the model as numeric variables. Code numbers were assigned to each variable of the remaining variables. The code numbers depend on the classification of each variable.

Table 5 illustrates the remaining variables that were coded.

\subsection{Data Sets}

The available data were divided into three sets: training set, cross-validation set and testing set. Training and cross validation sets are used in training the model through utilizing training set in modifying the network weights to minimize the network error, and monitoring this error by cross-validation set during the training process while the test set does not enter in the training process, thus, it has no effect on the training process. Testing set is used for measuring the generalization ability of the network, and evaluating network performance.

The available data (70 exemplars) were divided

Table 4 Input limitations in SVM Model.

\begin{tabular}{lll}
\hline Model's numeric variables & Minimum value & Maximum value \\
\hline Road area & $1,000 \mathrm{~m}^{2}$ & $73,000 \mathrm{~m}^{2}$ \\
Base course thickness & 0 & $11,000 \mathrm{~m}$ \\
Cut quantity & 0 & $150,000 \mathrm{~m}^{3}$ \\
Fill quantity & 0 & $13,500 \mathrm{~m}^{3}$ \\
Curbstone & 0 & $10,500 \mathrm{~m}^{3}$ \\
\hline
\end{tabular}


Table 5 Coding of variables.

\begin{tabular}{|c|c|c|}
\hline Factors & Code & Description \\
\hline \multirow{5}{*}{ Road surface type ( $\mathrm{C}$ means concrete) } & 1 & Asphalt (A) \\
\hline & 2 & Interlock (I) \\
\hline & 3 & $\mathrm{~A}+\mathrm{I}+\mathrm{C}$ \\
\hline & 4 & $\mathrm{~A}+\mathrm{I}$ \\
\hline & 5 & $\mathrm{I}+\mathrm{C}$ \\
\hline \multirow{3}{*}{ Base course type } & 0 & No base course \\
\hline & 1 & Crushed \\
\hline & 2 & Recycled \\
\hline \multirow{4}{*}{ Interlock thickness } & 0 & No interlock pavers \\
\hline & 1 & Interlock $8 \mathrm{~cm}$ \\
\hline & 2 & Interlock $6 \mathrm{~cm}$ \\
\hline & 3 & $8 \mathrm{~cm}+6 \mathrm{~cm}$ \\
\hline \multirow{4}{*}{ Asphalt thickness } & 0 & No asphalt pavement \\
\hline & 1 & Asphalt $8 \mathrm{~cm}$ \\
\hline & 2 & Asphalt $6 \mathrm{~cm}$ \\
\hline & 3 & $8 \mathrm{~cm}+6 \mathrm{~cm}$ \\
\hline \multirow{5}{*}{ Pipes diameters } & 0 & No pipes \\
\hline & 1 & $110 \sim 160 \mathrm{~mm}$ \\
\hline & 2 & $110 \sim 250 \mathrm{~mm}$ \\
\hline & 3 & $110 \sim 400 \mathrm{~mm}$ \\
\hline & 4 & $110 \sim 800 \mathrm{~mm}$ \\
\hline \multirow{7}{*}{ Manhole depth } & 0 & No manholes \\
\hline & 1 & up to $85 \mathrm{~cm}$ \\
\hline & 2 & $85 \sim 150 \mathrm{~cm}$ \\
\hline & 3 & $85 \sim 300 \mathrm{~cm}$ \\
\hline & 4 & $85 \sim 450 \mathrm{~cm}$ \\
\hline & 5 & $85 \sim 600 \mathrm{~cm}$ \\
\hline & 6 & $>600 \mathrm{~cm}$ \\
\hline \multirow{2}{*}{ Electrical works } & 0 & Not included \\
\hline & 1 & Included \\
\hline
\end{tabular}

randomly into three sets with the following ratios:

- Training set (includes 60 exemplars $\approx 85 \%$ );

- Cross validation set (includes 3 exemplars $\approx 5 \%$ );

- Testing set (includes 7 exemplars $\approx 10 \%$ ).

\subsection{Building Network}

Once all data were prepared, then the subsequent step is represented in creating the initial network by selecting the network type, number of hidden layers/nodes, transfer function, learning rule, and number of epochs and runs. However, before the model becomes ready, a supervised learning control was checked to specify the maximum number of epochs and the termination limits. Before starting the training phase, the normalization of training data is done to improve the performance of trained networks by Neurosolution program ranges from $(0 \sim+1)$. For more clarification, the output data will present the cost; Thus, the range must not be negative value.

\subsection{Model Training and Testing}

Dindar [18] stated that the objective of model training is to get a network that performs best on the data through training many networks on a training set and comparing the errors of the networks on the validation set. Therefore, several network parameters, such as the number of hidden layers, the number of hidden nodes, transfer functions and learning rules, 
were trained multiple times to produce the best weights for the model.

The model training comes after selecting the model type, which is SVM in this research. Three runs in each 1,000 epochs were applied, where a run is a complete presentation of 1,000 epochs, each epoch is a one complete presentation of all the data [19]. However, in each run, new weights were applied in the first epoch and then the weights were adjusted to minimize the percentage of error in other epochs. To avoid overtraining for the network during the training process, an option of using cross-validation was selected, which computes the error in a cross-validation set at the same time that the network is being trained with the training set.

The testing dataset was used for generalization that is to produce better output for unseen examples. Data from seven projects were used for testing purposes. A NeuroSolution test software throughout SVM tool was used for testing the adopted model according to the weights adopted. Table 6 presents the results of seven projects comparing the real cost of testing project with an estimated cost from the support vector machine model and an absolute error with both price and percentage is also presented.

The $M A E$ (mean absolute error) for the presented results in Table 6 equals USD29,217.44. It is largely acceptable for projects worth hundreds of thousands dollars. However, it is not a significant indicator for the model performance because it proceeds in one direction, where the mentioned error may be very simple if the total cost of the project is large.

The mean absolute percentage error of the model is calculated from the test cases, as shown in Table 6, which equals 5\%. This result can be expressed in another form by $A P$ (accuracy performance) according to Willmott and Matsuura [20] which is defined as (100 - MAPE) percentage:

$$
A P=100 \%-5 \%=95 \%
$$

That means the accuracy of the adopted model for building projects estimate in conceptual phase is $95 \%$. It is a good result, especially when this estimate in conceptual phase where no details or drawings are available.

Regression analysis was used to ascertain the relationship between the estimated cost and the actual cost. The results of linear regressing are illustrated graphically in Fig. 3. The correlation coefficient $(R)$ is 0.96 , indicating that there is a good linear correlation between the actual value and the estimated support vector machine cost of testing phase.

Fig. 4 describes the actual cost comparing with estimated costs for testing dataset. It is noted that there is a slight difference between two cost lines. In general, there is an agreement between the actual and the estimated.

As presented, the average estimate accuracy of the adopted model is 5\%. By comparing this estimate accuracy, where no drawings or details are available, with literature studies as Enshassi et al. [9] who stated that the level of accuracy for a project with no design work, it may range from $+40 \%$ to $-20 \%$. After preliminary design work, it may range from $+25 \%$ to $-10 \%$. On completion of detailed design work, it may range from $+10 \%$ to $-5 \%$, which clearly shows the high potential of the use of neural network models in cost estimate.

Table 6 Results of SVM model at testing phase.

\begin{tabular}{llll}
\hline Actual cost $(\$)$ & Model estimated cost $(\$)$ & AE (absolute error) $(\$)$ & Absolute percentage error \\
\hline $579,475.00$ & $608,338.24$ & $28,863.2$ & $5.0 \%$ \\
$562,725.00$ & $571,114.50$ & $8,389.5$ & $1.5 \%$ \\
$708,959.00$ & $658,934.52$ & $50,024.5$ & $7.1 \%$ \\
$674,415.00$ & $640,381.12$ & $34,033.9$ & $5.0 \%$ \\
$488,550.00$ & $468,101.67$ & $20,448.3$ & $4.2 \%$ \\
$687,820.00$ & $716,772.60$ & $28,952.6$ & $4.2 \%$ \\
$394,845.00$ & $428,655.07$ & $33,810.1$ & $8.6 \%$ \\
\hline
\end{tabular}




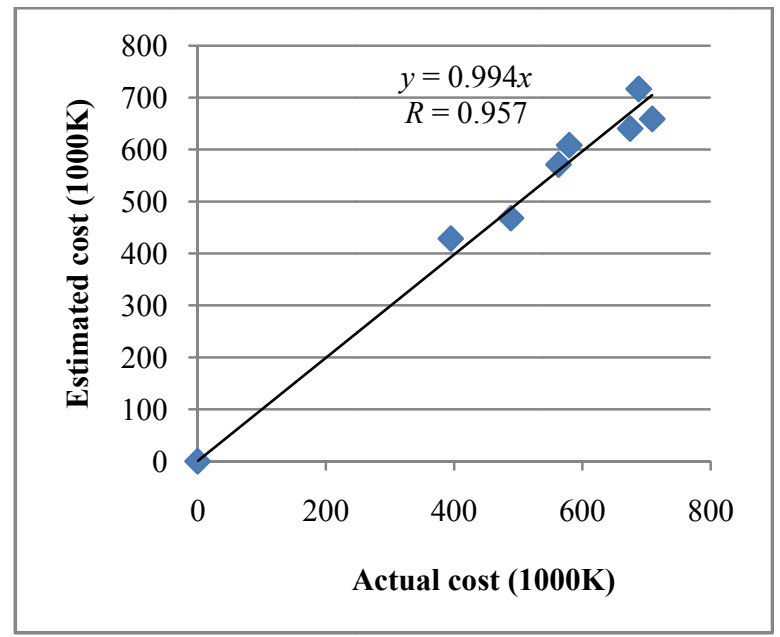

Fig. 3 Linear regressions of actual and estimated costs.

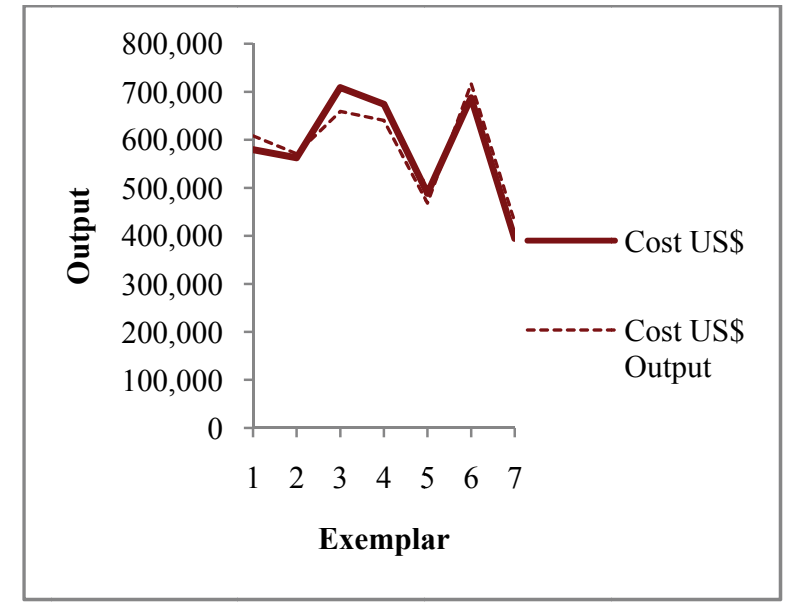

Fig. 4 Desired output and actual network output for testing dataset.

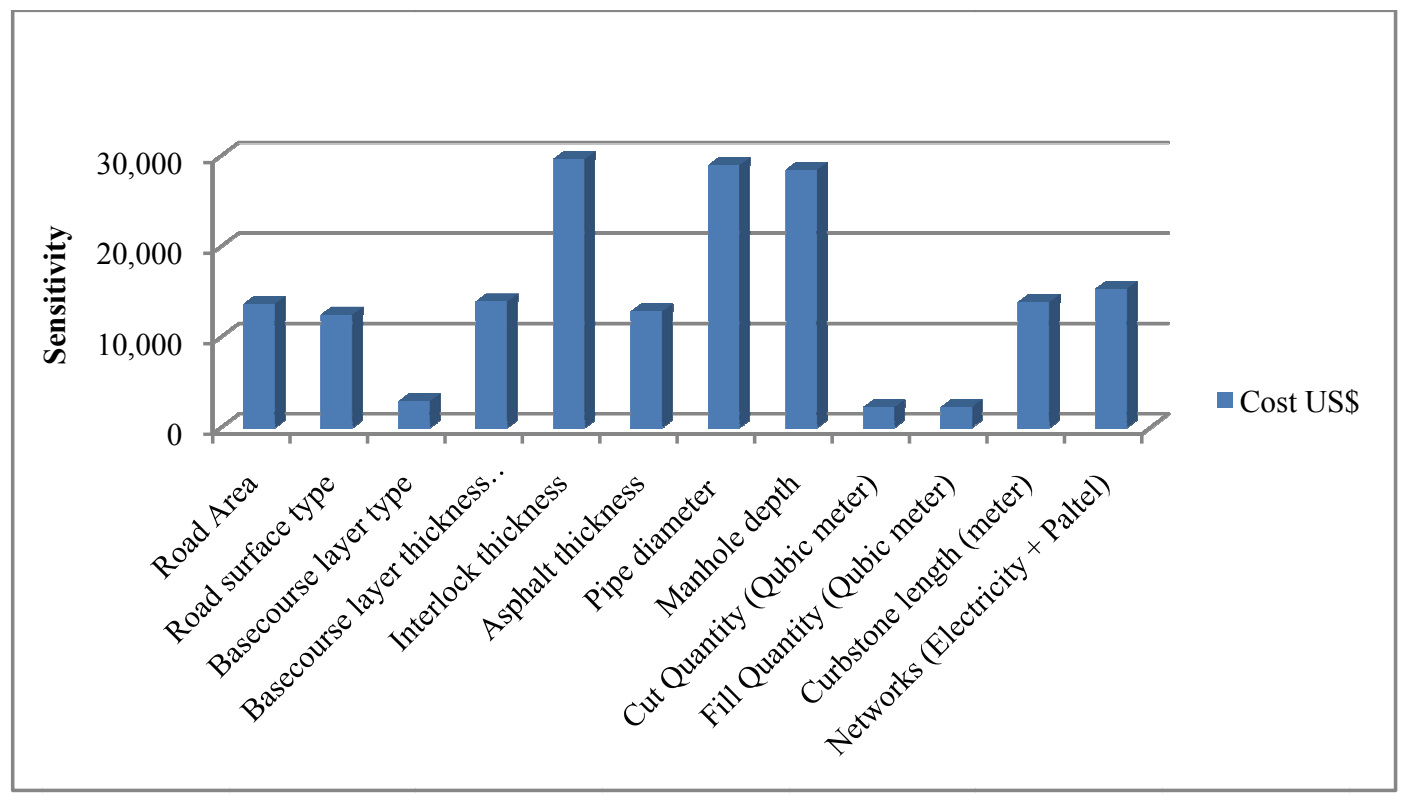

Fig. 5 Sensitivity about the mean.

\subsection{Sensitivity Analysis}

Sensitivity analysis was carried out by NeuroSolution (SVM) tool to evaluate the influence of each input parameter to output variable for understanding the significance effect of input parameters on model output. Fig. 5 presents the sensitivity analysis results for each input parameter.

The increase of standard deviation refers to the strong influence of this parameter on the overall cost of the project. Fig. 5 shows that the interlock thickness has the highest rate of influence on the total cost of projects, pipe diameter as a second sensitive factor, then the manhole depth and so on.

\section{Conclusions}

In this paper, a model based on support vector machine was developed to estimate the parametric cost of road projects. The presented model provided the SVM with a greater potential to generalize the input-output relationship learnt during its training phase for making suitable estimations for new input data. The most important factors that affect the cost estimation of road projects were identified as input 
parameters in SVM model. The total project cost was considered as an output. Seventy case studies for the model development were used. The developed model was successfully able to predict the road project cost with $95 \%$ performance accuracy. The model gives a chance for fast and easy cost estimation at early stages of project preparation. In future research, it is recommended to compare the results of this model with other tools like regression models and Artificial Neural Networks.

\section{References}

[1] Ayed, A. M. 1997. "Parametric Cost Estimating of Highway Projects Using Neural Networks.” M.Sc. thesis, National Library of Canada Memorial University of Newfoundland.

[2] Cheng, M. Y., and Wu, Y. W. 2005. "Construction Conceptual Cost Estimates Using Support Vector Machine." Presented at 22nd International Symposium on Automation and Robotics in Construction, Ferrara, Italy.

[3] Iyer, K. C., and Jha, K. N. 2005. "Factors Affecting Cost Performance: Evidence from Indian Construction Projects." International Journal of Project Management 23 (4): 283-95.

[4] Rahman, I. A., Memon, A. H., and Karim A. T. A. 2013. "Relationship between Factors of Construction Resources Affecting Project Cost." Canadian Center of Science and Education 7 (1): 67-75.

[5] Memon, H. 2010. "Factors Affecting Construction Cost in Mara Large Construction Project: Perspective of Project Management Consultant." International Journal of Sustainable Construction Engineering and Technology 1 (2): 41-54.

[6] Mahamid, I., and Bruland, A. 2010. "Preliminary Cost Estimating Models for Road Construction Activities." Presented at FIG (International Federation of Surveyors) Congress 2010: Facing the Challenges-Building the Capacity, Sydney, Australia.

[7] Sinnette, J. 2007. Major Project Program Cost Estimating Guidance. FHWA Office of Innovative Program Delivery. Accessed July 4, 2014. http://www.fhwa.dot.gov/ipd/ project_delivery/tools_programs/cost_estimating/guidan ce.aspx.

[8] Oberlender, G. 1993. Project Management for Engineers. New York: McGraw-Hill Companies.

[9] Enshassi, A., Mohammed, S., and Madi, I. 2007. "Cost Estimation Practice in Gaza Strip: A Case Study." The Islamic University Journal 15 (2): 153-76.

[10] Pheng, L. S., and Chuan, Q. T. 2006. "Environmental Factors and Work Performance of Project Managers in the Construction Industry." International Journal of Project Management 24 (1): 24-37.

[11] Chan, D., and Kumaraswamy, M. 1996. “An Evaluation of Construction Time Performance in the Building Industry." Building and Environment 31 (6): 569-78.

[12] Gunner, J., and Skitmore, M. 1999. "Comparative Analysis of Pre-bid Forecasting of Building Prices Based on Singapore Data." Construction Management and Economics 17 (5): 635-46.

[13] Mahmmid, I. 2013. "Effects of Project's Physical Characteristics on Cost Deviation in Road Construction." Journal of King Saud University-Engineering Sciences 25 (1): 81-8.

[14] El Asmar, M., Hanna, A., and Whited, G. 2011. "New Approach to Developing Conceptual Cost Estimates for Highway Projects." Journal of Construction Engineering and Management 137 (11): 942-9.

[15] Lin, C. F., and Wang, S. D. 2002. "Fuzzy Support Vector Machine.” IEEE Transactions on Neural Networks 13 (2): 464-71.

[16] Gopalakrishnan, K., and Kim, S. 2011. "Support Vector Machines Approach to HMA Stiffness Prediction." Journal of Engineering Mechanics 137 (2): 138-46.

[17] Tabatabaee, N., Ziyadi, M., and Shafahi, Y. 2013. "Two-Stage Support Vector Classifier and Recurrent Neural Network Predictor for Pavement Performance Modeling." Journal of Road Systems 19 (3): 266-74.

[18] Dindar, Z. A. 2004. "Artificial Neural Networks Applied to Option Pricing." Master thesis, University of the Witwatersrand.

[19] Principe, J., Lefebvre, C., Lynn, G., Fancourt, D., and Wooten, D. 2010. NeuroSolution Help. New York: NeuroDimension, Inc.

[20] Willmott, C. J., and Matsuura, K. 2005. "Advantages of the Mean Absolute Error (MAE) over the Root Mean Square Error (RMSE) in Assessing Average Model Performance." Climate Research 30 (1): 79-82. 